\title{
Originals
}

\section{Impaired autoregulation of glomerular filtration rate in Type 1 (insulin-dependent) diabetic patients with nephropathy}

\author{
H.-H. Parving 1, 2, 4 , H. Kastrup ${ }^{1,2,3}$, U. M. Smidt ${ }^{2}$, A. R. Andersen ${ }^{4}$, B. Feldt-Rasmussen ${ }^{4}$ and J.Sandahl Christiansen ${ }^{4}$ \\ ${ }^{1}$ Hvidöre Hospital, Klampenborg, ${ }^{2}$ Department of Clinical Physiology, Bispebjerg Hospital, Copenhagen, \\ ${ }^{3}$ Medical Department F, Herlev Hospital, Copenhagen, ${ }^{4}$ Steno Memorial Hospital, Gentofte, Denmark
}

\begin{abstract}
Summary. The effect of acute lowering of arterial blood pressure upon kidney function in nephropathy was studied in 13 patients with long-term Type 1 (insulin-dependent) diabetes. Ten normal subjects (six normotensive and four hypertensive) and five short-term Type 1 diabetic patients without nephropathy served as controls. Renal function was assessed by glomerular filtration rate (single bolus ${ }^{51} \mathrm{Cr}$-EDTA technique) and urinary albumin excretion rate (radial immunodiffusion). The study was performed twice within 2 weeks, with the subjects receiving an intravenous injection of either clonidine $(225 \mu \mathrm{g})$ or saline $(0.154 \mathrm{mmol} / 1)$. The arterial blood pressure was similar in the diabetic patients with nephropathy (mean $\left.\frac{136 \pm 11}{88 \pm 5} \mathrm{mmHg}\right)$ and in the non-diabetic control subjects (mean $\frac{140 \pm 25}{92 \pm 15} \mathrm{mmHg}$ ). The clonidine injection induced sim-
\end{abstract}

ilar reductions in mean arterial blood pressure in all three groups $(16-18 \mathrm{mmHg})$. While glomerular filtration rate and urinary albumin excretion rate remained unchanged in both control groups after clonidine injection, glomerular filtration rate dimished from 78 to $71 \mathrm{ml} / \mathrm{min}$ per $1.73 \mathrm{~m}^{2}(p<0.01)$, and urinary albumin excretion declined from 1707 to $938 \mu \mathrm{g} / \mathrm{min}$ $(p<0.01)$ in the patients with diabetic nephropathy. Our results suggest that an intrinsic vascular (arteriolar) mechanism underlying the normal autoregulation of glomerular filtration rate, i.e. the relative constancy of glomerular filtration rate that occurs in response to rather wide variations in perfusion pressure, is defective in diabetic nephropathy.

Key words: Autoregulation, arterial blood pressure, glomerular filtration, diabetic nephropathy, Type 1 diabetes
Nearly $50 \%$ of all Type 1 diabetic patients develop persistent proteinuria, a decline in glomerular filtration rate (GFR) and elevated blood pressure, the clinical syndrome of diabetic nephropathy [1-3]. Renal failure due to nephropathy is the leading cause of death in Type 1 diabetes $(30 \%)[3,4]$. Elevated blood pressure accelerates nephropathy $[5,6]$. Recent studies indicate that early and effective anti-hypertensive treatment may reduce albuminuria and the decline in GFR in Type 1 diabetic patients with nephropathy $[7,8,9]$. In our own studies, approximately $35 \%$ of the patients showed a stepwise reduction in GFR ( $\geqslant 10 \%$ of the pretreatment values) at the start of aggressive anti-hypertensive treatment $[9,10]$. This finding led us to suggest that the mechanisms underlying the normal autoregulation of GFR, i.e. the maintenance of GFR within normal limits during changes in perfusion pressure induced by changing arterial pressure, might be defective in diabetic nephropathy. To evaluate this hypothesis we investigated the effect of acute blood pressure reduction upon GFR in Type 1 diabetic patients with nephropathy.

\section{Subjects and methods}

\section{Subjects}

Thirteen Type 1 diabetic patients with nephropathy were investigated (Table 1). All patients were characterized by persistent proteinuria $(>0.5 \mathrm{~g} / 24 \mathrm{~h})$, serum creatinine $<200 \mu \mathrm{mol} / \mathrm{l}$, age $<50$ years, onset of Type 1 diabetes before the age of 31 years and no blindness. The mean duration of diabetes was 22 years (range 17-32 years). All were insulin-dependent from the time of diagnosis and all received two daily injections of highly purified porcine insulin (mean dose $0.60 \mathrm{U}$. $\mathrm{kg}^{-1} \cdot$ day $^{-1}$ ). Patient 1 received $100 \mathrm{mg}$ Metoprolol daily (Hässle, Söder Täjle, Sweden), while none of the remaining 12 was taking drugs other than insulin. Nephropathy was diagnosed clinically according to previously described criteria [9]. Furthermore, a kidney biopsy had been performed in all patients except nos. 1,9, and 10. Nodular diabetic glomerulosclerosis was found in two patients, while diffuse diabetic glomerulosclerosis was demonstrated in the remaining eight patients. Varying degree of arteriolar hyalinosis was present in all 10 biopsy specimens.

The non-diabetic control group consisted of six normotensive and four subjects with essential hypertension matched for sex, age and blood pressure levels (Tables a and 2). Subject 8 received $100 \mathrm{mg}$ of Metoprolol daily, while none of the remaining subjects was taking drugs. 
Table 1. Clinical data of Type 1 diabetic patients with and without nephropathy and non-diabetic control subjects

\begin{tabular}{|c|c|c|c|c|c|}
\hline Subjects & Sex & $\begin{array}{l}\text { Age } \\
\text { (years) }\end{array}$ & $\begin{array}{l}\text { Duration } \\
\text { of } \\
\text { diabetes } \\
\text { (years) }\end{array}$ & $\begin{array}{l}\text { Insulin } \\
\text { dose } \\
\left(\mathrm{U} \cdot \mathrm{kg}^{-1}\right. \\
\text { day }\end{array}$ & Retinopathy \\
\hline \multicolumn{6}{|c|}{ Type 1 diabetic patients with nephropathy } \\
\hline 1 & M & 45 & 26 & 0.61 & Proliferative \\
\hline 2 & $\mathrm{~F}$ & 35 & 20 & 0.68 & Proliferative \\
\hline 3 & $\mathrm{~F}$ & 34 & 21 & 0.45 & Proliferative \\
\hline 4 & M & 36 & 21 & 0.57 & Proliferative \\
\hline 5 & $\mathrm{M}$ & 39 & 18 & 0.58 & Background \\
\hline 6 & $\mathrm{M}$ & 40 & 27 & 0.51 & Proliferative \\
\hline 7 & M & 34 & 22 & 0.61 & Proliferative \\
\hline 8 & M & 34 & 32 & 0.59 & Proliferative \\
\hline 9 & M & 34 & 24 & 0.79 & Proliferative \\
\hline 10 & $F$ & 29 & 17 & 0.70 & Background \\
\hline 11 & $\mathbf{M}$ & 25 & 17 & 0.65 & Background \\
\hline 12 & M & 39 & 17 & 0.52 & Background \\
\hline 13 & $\mathbf{M}$ & 33 & 18 & 0.52 & Background \\
\hline \multicolumn{2}{|c|}{ Mean \pm SD } & $35 \pm 5$ & $22 \pm 5$ & $0.60 \pm 0.09$ & \\
\hline \multicolumn{6}{|c|}{ Type 1 diabetic patients without nephropathy } \\
\hline 1 & $\mathrm{M}$ & 34 & 5 & 0.45 & Nil \\
\hline 2 & M & 29 & 8 & 0.58 & $\mathrm{Nil}$ \\
\hline 3 & $\mathrm{M}$ & 35 & 6 & 0.70 & Nil \\
\hline 4 & $\mathrm{M}$ & 43 & 7 & 0.50 & Nil \\
\hline 5 & $\mathrm{M}$ & 31 & 8 & 0.66 & Nil \\
\hline \multicolumn{2}{|c|}{ Mean $\pm \mathrm{SD}$} & $34 \pm 5$ & $7 \pm 1$ & $0.58 \pm 0.10$ & \\
\hline \multicolumn{6}{|c|}{ Control subjects } \\
\hline 1 & $\mathrm{~F}$ & 35 & & & \\
\hline 2 & $\mathrm{M}$ & 35 & & & \\
\hline 3 & $\mathrm{M}$ & 32 & & & \\
\hline 4 & $\mathrm{M}$ & 32 & & & \\
\hline 5 & $\mathrm{~F}$ & 36 & & & \\
\hline 6 & $\mathrm{~F}$ & 25 & & & \\
\hline 7 & $F$ & 33 & & & \\
\hline 8 & M & 50 & & & \\
\hline 9 & $\mathrm{M}$ & 30 & & & \\
\hline 10 & $\mathrm{M}$ & 45 & & & \\
\hline \multicolumn{2}{|c|}{ Mean $\pm S D$} & $35 \pm 7$ & & & \\
\hline
\end{tabular}

Five short-term Type 1 diabetic patients without proteinuria or retinopathy were also studied (Table 1). The duration of diabetes ranged from 5 to 8 years. The patients were ketosis-prone and were treated with insulin twice daily (mean dose $0.58 \mathrm{U} \cdot \mathrm{kg}^{-1} \cdot \mathrm{day}^{-1}$ ). None of the patients was taking other drugs.

All diabetic patients and the control subjects gave their informed consent, and the experimental design was approved by the local Ethical Committee.

\section{Methods}

The study was performed twice within 2 weeks, with the subjects receiving a slow intravenous, injection $(10 \mathrm{~min})$ at $08.40 \mathrm{~h}$ of either clonidine ( $225 \mathrm{~kg}$, Boehringer, Ingelheim, FRG) or saline $(0.154 \mathrm{mmol} / \mathrm{l})$, in random order. Measurements were taken in the morning following an overnight fast. The diabetic patients had their last injection of insulin at $17.00 \mathrm{~h}$ the day before the study. The patients drank tap-water $(200 \mathrm{ml} / \mathrm{h})$ during the study. Measurements were performed in the supine position.

GFR was measured after a single intravenous injection of ${ }^{51} \mathrm{Cr}$ EDTA $(09.00 \mathrm{~h})$ by studying the plasma disappearance for $4 \mathrm{~h}$, as described by Bröchner-Mortensen et al. [11]. The mean intra-individual coefficient of variation for GFR was $4.1 \%$. Urinary albumin excretion was measured during the 4 -h clearance period using the radial im- munodiffusion technique [12]. This assay has a sensitivity of $3 \mathrm{mg} / 1$ and an inter-assay coefficient of variation of $5.5 \%$. Blood pressure was measured with a standard sphygmomanometer (cuff $25 \times 12 \mathrm{~cm}$ ) on the right arm. Blood pressure was measured every $15 \mathrm{~min}$ after clonidine injection and every hour during the control experiments. Diastolic blood pressure was recorded at the disappearance of the Korotkoff sounds (phase 5). Blood glucose was measured every hour during the 4-h clearance period by a glucose-oxidase method on an autoanalyzer (Model II, Technicon, Tarrytown, New York, USA).

\section{Statistical analysis}

In all cases the paired and unpaired Student's t-test (two-tailed) was used.

\section{Results}

The arterial blood pressure was the same in the diabetic patients with nephropathy and in the non-diabetic control subjects (mean $\frac{136 \pm 11}{88 \pm 5}$ versus $\frac{140 \pm 25}{92 \pm 15} \mathrm{mmHg}$; Table 2). Blood pressure was significantly lower in the short-term diabetic patients (mean $\frac{127 \pm 19}{80 \pm 11} \mathrm{mmHg}$; $\mathrm{p}<0.05$ ). Intravenous clonidine injection induced an equal reduction in mean arterial blood pressure (MAP) in all three groups (average $16-18 \mathrm{mmHg}$ ). MAP was reduced to just below $80 \mathrm{mmHg}$ in three to four subjects in each group. Blood pressure reduction remained stable during the 4-h clearance procedure (Table 3 ). Heart rate was equally reduced in all three groups (average $8-11$ beats $/ \mathrm{min}$ ) after clonidine injection.

Eleven out of 13 patients with nephropathy had a significant reduction in GFR after clonidine injection (mean difference $7 \mathrm{ml} / \mathrm{min}$ per $1.73 \mathrm{~m}^{2} ; p<0.01$; Table 2). In contrast, GFR remained unchanged in the short-term diabetic and non-diabetic control subjects.

The relationship between MAP and the relative GFR before and after acute blood pressure reduction is shown in Figure 1. A significant linear correlation between the reduction in MAP and relative GFR was found in the patients with nephropathy $(r=0.57 ; p<$ $0.05)$. This relationship was lacking in the two control groups.

Figure 2 shows that the reduction in relative GFR was below the lower limit of normal autoregulation in seven out of 13 patients with diabetic nephropathy.

Albuminuria diminished in 12 out of the 13 patients with nephropathy after clonidine injection (mean $983 \pm 529 \mu \mathrm{g} / \mathrm{min}$ compared with a pre-treatment level of $1707 \pm 1130 \mu \mathrm{g} / \mathrm{min} ; p<0.01)$. Urinary albumin excretion remained unchanged in the two control groups.

The blood glucose concentration in the short-term diabetic patients, measured every hour during the 4-h clearance period, was identical in the control studies (mean $12.2 \pm 4.1 \mathrm{mmol} / \mathrm{l}$ ) and the hypotensive studies (mean $12.0 \pm 4.0 \mathrm{mmol} / \mathrm{l}$ ). Blood glucose was slightly higher during the control studies (mean 13.1士 
Table 2. Arterial blood pressure, glomerular filtration rate and urinary albumin excretion before and during acute blood pressure reduction in Type 1 diabetic patients with and without nephropathy and in non-diabetic control subjects

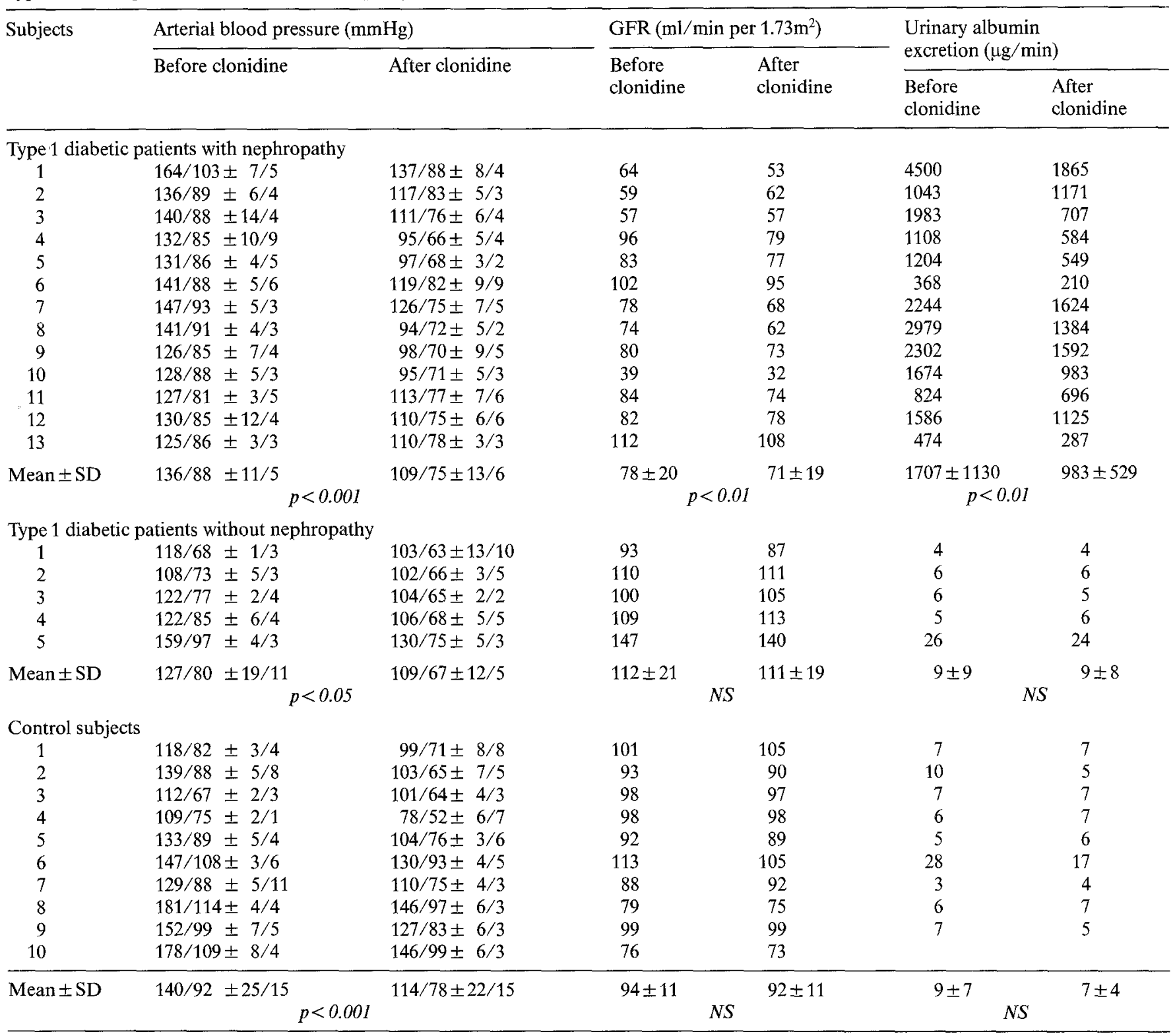

Results expressed as mean $\pm \mathrm{SD}$

Table 3. Time course of blood pressure response to intravenous clonidine injection in Type 1 diabetic patients with and without nephropathy and in non-diabetic control subjects.

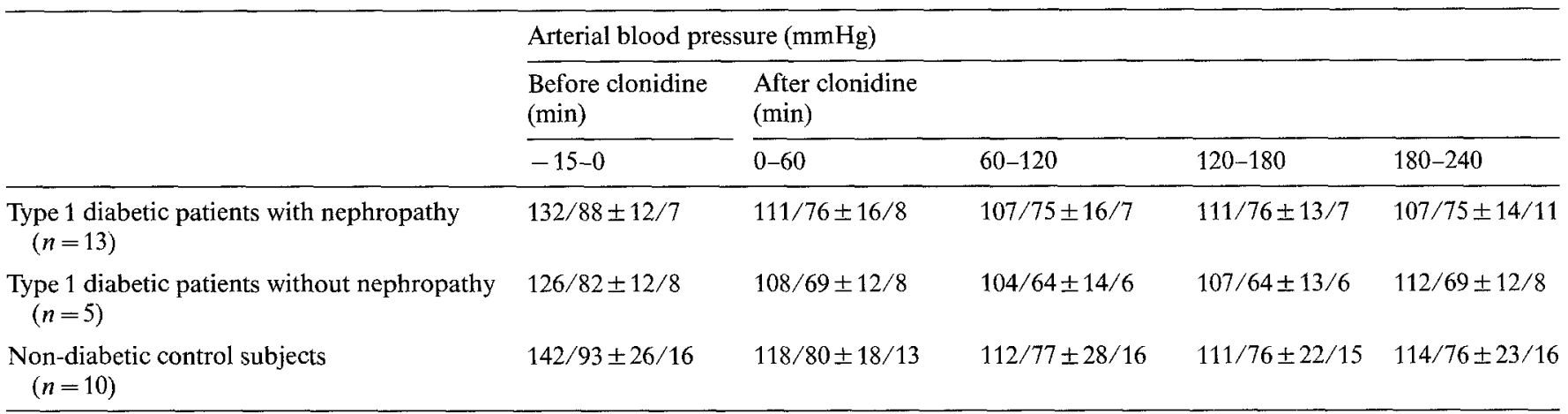

Results expressed as mean $\pm \mathrm{SD}$ 


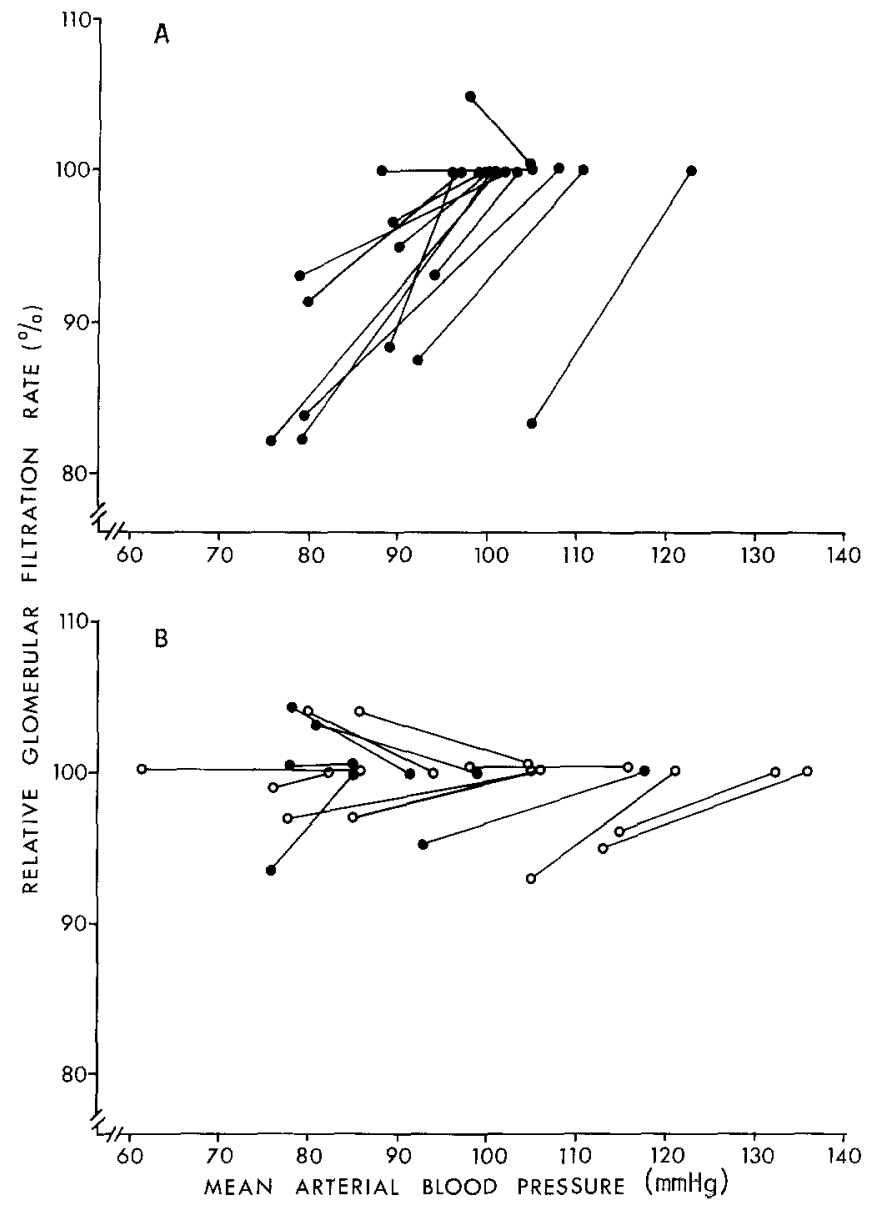

Fig. $1 \mathrm{~A}$ and $\mathrm{B}$. Relative glomerular filtration rate (percentage of control GFR) and mean arterial blood pressure before and after intravenous injection of clonidine. A Thirteen Type 1 diabetic patients with nephropathy; B five short-term Type 1 diabetic patients without nephropathy $(\mathbf{O})$ and ten non-diabetic control subjects $(O)$

$5.5 \mathrm{mmol} / 1$ ) compared with the clonidine studies (mean $10.6 \pm 5.2 \mathrm{mmol} / \mathrm{l})$ in the patients with nephropathy $(p>0.10)$.

Apart from a dry mouth and sleepiness no serious side-effects were observed after clonidine injection.

\section{Discussion}

The major observation in our study is the demonstration of impaired autoregulation of GFR in long-term Type 1 diabetic patients with nephropathy. It should be mentioned that a wide variation in response to acute blood pressure reduction ranging from normal to severely impaired autoregulation was demonstrated. A complete pressure-passive vasculature was found in four out of 13 patients with nephropathy ( $\triangle \mathrm{GFR} \%=$ $\triangle \mathrm{MAP} \%$ ). Aggressive antihypertensive treatment induced an equal response ( $\triangle \mathrm{GFR} \%=\triangle \mathrm{MAP} \%)$ in eight out of 22 long-term Type 1 diabetic patients with nephropathy $[9,10]$. GFR remained unchanged in the short-term Type 1 diabetic patients without clinical microangiopathy and in the non-diabetic control group.

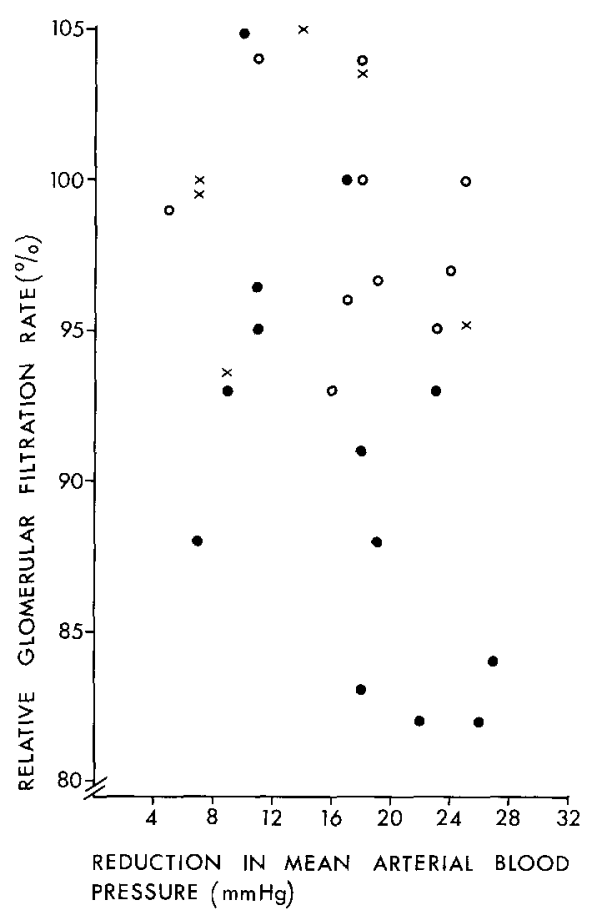

Fig. 2. Relative glomerular filtration rate (percentage of control GFR) and the reduction in mean arterial blood pressure induced by intravenous injection of clonidine. Thirteen Type 1 diabetic patients with nephropathy $(\bullet)$, five short-term Type 1 diabetic patients without nephropathy $(x)$ and ten non-diabetic control subjects $(O)$

The base-line blood pressure levels and the reduction in blood induced by intravenous injection of clonidine were nearly the same in the patients with nephropathy and in the control subjects.

It is well documented that strict metabolic control reduces GFR and urinary albumin excretion in Type 1 diabetic patients without nephropathy [13]. This metabolic effect on GFR and albuminuria is lacking in diabetic nephropathy $[14,15]$. Thus it seems highly unlikely that the present small difference in metabolic control had any impact on the measured variables in our patients with nephropathy.

Our reasons for selecting clonidine as a hypotensive drug were its lack of direct pharmacological effects on the renal vessels [16-18], its predictable effectiveness and safety in inducing a prolonged fall in arterial pressure lasting $5-7 \mathrm{~h}$ after intravenous injection. Intravenous bolus injection of clonidine has a brief direct alpha-adrenergic stimulating effect lasting a few minutes (hypertension), followed by a prolonged suppression of the central nervous system's sympathetic centres (hypotension) $[16,18]$. No peripheral sympathetic inhibition has been demonstrated. In an attempt to avoid the 
initial rise in blood pressure, we injected clonidine slowly intravenously (10 min). Intravenous injection of clonidine in normo- and hypertensive subjects induces a slight but insignificant reduction in peripheral and renal vein renin concentration $[17,18]$. The decrease in blood pressure is due to diminished cardiac output, not to effects on total peripheral resistance $[16,17]$. Intravenous injection of clonidine $(150-300 \mu \mathrm{g})$ to normo- and hypertensive subjects induces no significant changes in renal plasma flow and GFR $[17,18]$.

Autoregulation of GFR, i.e. the maintenance of relative constancy of GFR despite variations in mean arterial blood pressure above $80 \mathrm{mmHg}$, is present in animals and man $[19,20,21,22]$. This phenomenon is demonstrated in innervated, denervated and isolated kidneys $[23,24]$ and thus believed to be mediated by mechanisms intrinsic to the kidney. Studies in the $\mathrm{Mu}$ nich-Wistar rat suggest that autoregulation of GFR is due to autoregulation of two of the main GFR determinants, i.e. renal plasma flow and glomerular capillary hydraulic pressure [23]. Our finding of a considerable decrease in albuminuria induced by acute blood pressure reduction suggests diminished glomerular capillary hydraulic pressure. This finding also suggests that albuminuria in diabetic nephropathy is pressure-dependent to a large extent. Effective long-term antihypertensive therapy diminished albuminuria in diabetic nephropathy $[7,9]$.

Impaired autoregulation of renal plasma flow may also contribute to the impaired autoregulation of GFR in diabetic nephropathy, but information is completely lacking at the moment. The mechanisms underlying the compensatory changes in kidney vascular (arteriolar) resistance during changes in arterial blood pressure are unknown [23]. But the afferent arteriole is the main locus of the resistance change [23]. The basis for the impaired GFR autoregulation in diabetic nephropathy might involve either structural changes (arteriolar hyalinosis) and/or functional disturbance of smooth muscle reducing the reactivity. Arteriolar hyalinosis was demonstrated in all our 10 patients who, for diagnostic purposes, had undergone a kidney biopsy. The hyaline deposits of the arteriolar wall might impair the normal myogenic responses to pressure changes.

In addition to the myogenic and metabolic concepts for autoregulation of blood flow in general, humoral substances, e. g. prostaglandins and the renin-angiotensin system, have been suggested in the autoregulation of renal plasma flow and GFR [23, 24]. However, prostaglandin synthetase inhibitors and angiotensin II antagonists failed to interfere with autoregulation in the majority of studies performed $[23,24]$.

Bentsen et al. [25] originally demonstrated impaired autoregulation of cerebral blood flow in some longterm diabetic patients with clinical microangiopathy. Impaired autoregulation of blood flow in skeletal muscle and subcutaneous tissue has been demonstrated in long-term Type 1 patients with diabetic retinopathy and nephropathy [26]. Recently, Sinclair et al. [27] have found impaired autoregulation of retinal blood flow in diabetic simplex retinopathy and nearly complete lack of autoregulation in proliferative diabetic retinopathy. A likely explanation for the present and the previous findings of impaired autoregulation of blood flow in many tissues may be hyalinosis of the arterioles.

The clinical significance of impaired autoregulation of blood flow is hypoperfusion during arterial hypotension, e.g. sleep, and hyperperfusion during hypertensive episodes, e.g. stress and physical exertion. The latter is particularly important since patients who have had diabetes for some years have a higher blood pressure response to exercise than normal controls [28]. Furthermore, intrarenal hypertension is an important factor in the development and progression of diabetic nephropathy [29-31]. Despite the reduction in GFR at the start of effective antihypertensive treatment, long-term observations clearly indicate that careful blood pressure control slows the progression of diabetic nephropathy [7-9].

Acknowledgements. We wish to express our gratitude for the support we have received from The Danish Medical Research Council and The Danish Diabetes Foundation.

\section{References}

1. Knowles HC (1974) Magnitude of the renal failure problem in diabetes. Kidney Int $6: 2-7$

2. Ireland JT, Viberti GC, Watkins PJ (1982) The kidney and renal tract. In: Keen H, Jarrett RJ (eds) Complications of diabetes, 2nd eds. E. Arnold, London, pp 152-172

3. Deckert T, Poulsen JE, Larsen M (1978) Prognosis of diabetes with diabetes onset before the age of thirty-one. I. Survival, causes of death and complications. Diabetologia 14: 363-370

4. Andersen AR, Christiansen JS, Andersen JK, Kreiner S, Deckert T (1983) Diabetic nephropathy in Type 1 (insulin-dependent) diabetes: an epidemiological study. Diabetologia 25: 496-501

5. Berkman J, Rifkin H (1973) Unilateral nodular diabetic glomerulosclerosis (Kimmelstiel-Wilson). Report of a case. Metab Clin Exp 22: 715-722

6. Mauer SM, Steffes MW, Azar S, Sandberg SK, Brown DM (1978) The effect of Goldblatt hypertension on development of the glomerular lesions of diabetes mellitus in the rat. Diabetes 27: $738-744$

7. Mogensen CE (1982) Long-term antihypertensive treatment inhibiting progression of diabetic nephropathy. $\mathrm{Br}$ Med $\mathrm{J} 285$ : 685-688

8. Parving $\mathrm{H}-\mathrm{H}$, Andersen AR, Smidt UM, Christiansen JS, Oxenböll B, Svendsen PAa (1983) Diabetic nephropathy and arterial hypertension: the effect of antihypertensive treatment. Diabetes 32 (Suppl 2): 83-87

9. Parving H-H, Andersen AR, Smidt UM, Svendsen PAa (1983) Early aggressive antihypertensive treatment reduces rate of decline in kidney function in diabetic nephropathy. Lancet 1 : 1175-1179

10. Parving H-H, Andersen AR, Smidt UM, Friisberg B, Svendsen PAa (1981) Reduced albuminuria during early and aggressive antihypertensive treatment of insulin-dependent diabetics with diabetic nephropathy. Diabetes Care 4: 459-463

11. Bröchner-Mortensen J, Giese J, Rossing N (1969) Renal inulin clearance versus total plasma clearance of ${ }^{51} \mathrm{Cr}$-EDTA. Scand $\mathbf{J}$ Clin Lab Invest 23: 301-305 
12. Mancini G, Carbonara AO, Heremans JF (1965) Immunochemical quantitation of antigens by single radial immunodiffusion. Immunochemistry $2: 235-254$

13. Parving H-H, Noer I, Deckert T, Evrin P-E, Nielsen SL, Lyngsøe J, Mogensen CE, Rørth M, Svendsen PAa, Trap-Jensen J, Lassen NA (1976) The effect of metabolic regulation on microvascular permeability to small and large molecules in short-term diabetics. Diabetologia 12: 161-166

14. Viberti GC, Bilous RW, Mackintosh D, Bending JJ, Keen H (1983) Long-term correction of hyperglycaemic and progression of renal failure in insulin-dependent diabetes. Br Med $\mathbf{J} 286$ : 598-602

15. Christiansen J, Parving HH (1984) The effect of short-term strict metabolic control on albuminuria in insulin-dependent diabetics with normal kidney function and diabetic nephropathy. Diabetic Nephropathy 3: 127-129

16. Onesti G, Bock KD, Heimsoth V, Kim KE, Merguet P (1971) Clonidine: a new antihypertensive agent. Am J Cardiol: 28: 74-83

17. Onesti G, Schwartz AB, Kim KE, Paz-Martinez V, Swartz C (1971) Antihypertensive effect of clonidine. Circ Res 28 (Suppl II): 53-69

18. Brod J, Horbach L, Just H, Rosenthal J, Nicolescu R (1972) Acute effects of clonidine on central and peripheral haemodynamics and plasma renin activity. Eur J Clin Pharm 4: 107-114

19. Forster RP, Maes JP (1947) Effect of experimental neurogenic hypertension on renal blood flow and glomerular filtration rate in intact denervated kidneys of unanesthetized rabbits with adrenal glands demedulated. Am J Physiol 150: 534-540

20. Selkurt EE, Hall PW, Spencer MP (1949) Influence of graded arterial pressure decrement on renal clearance of creatinine, p-aminohippurate and sodium. Am J Physiol 159: 369-378

21. Shipley RE, Study RS (1951) Changes in renal blood flow, extraction of insulin, glomerular filtration rate, tissue pressure and urine flow with acute alteration of renal artery blood pressure. Am J Physiol 167: 676-688

22. Thurau K (1964) Renal hemodynamics. Am J Med 36: 698-719
23. Brenner BM, Ichikawa J, Deen WM (1981) Glomerular filtration. In: Brenner BM, Rector FC (eds) The kidney. WB Saunders, Philadelphia, pp 300-302

24. Beeuwkes III R, Ichikawa J, Brenner BM (1981) The renal circulation. In: Brenner BM, Rector FC (eds) The kidney. WB Saunders, Philadelphia, pp 278-282

25. Bentsen N, Larsen B, Lassen NA (1975) Chronically impaired autoregulation of cerebral blood flow in long-term diabetics. Stroke 6: $497-502$

26. Faris J, Vagn Nielsen $H$, Henriksen O, Parving H-H, Lassen NA (1983) Impaired autoregulation of blood flow in skeletal muscle and subcutaneous tissue in long-term diabetic patients with microangiopathy. Diabetologia 25: 486-488

27. Sinclair SH, Grunwald JE, Riva C, Braunstein SN, Nichols CW, Schwartz SS (1982) Retinal vascular autoregulation in diabetes mellitus. Ophthalmology 89: 748-750

28. Karlefors T (1966) Exercise test in male diabetics. Acta Med Scand, Suppl 499

29. Steffes MW, Brown DM, Mauer SM (1979) The development, enhancement, and reversal of secondary complications of diabetes mellitus. Human Pathol 10: 293-299

30. Hostetter TH, Rennke HG, Brenner BM (1982) The case for intrarenal hypertension in the initiation and progression of diabetic and other glomerulopathies. Am J Med 72:375-380

31. Parving $\mathrm{H}-\mathrm{H}$, Viberti GC, Keen $\mathrm{H}$, Christiansen IS, Lassen NA (1983) Hemodynamic factors in the genesis of diabetic microangiopathy. Metabolism 32: 943-949

Received: 26 March 1984

and in revised form: 8 August 1984

Dr. H.-H. Parving

Hvidöre Hospital

Emiliekildevej 1

DK-2930 Klampenborg, Denmark 